\title{
Gas Sensing Properties and In Situ Diffuse Reflectance Infrared Fourier Transform Spectroscopy Study of Acetone Adsorption and Reactions on $\mathrm{SnO}_{2}$ Films
}

\author{
Zhenxin Zhang ${ }^{1}$, Kaijin Huang ${ }^{1,2,3, *}$, Fangli Yuan ${ }^{2}$ and Changsheng Xie ${ }^{1}$ \\ 'State Key Laboratory of Materials Processing and Die \& Mould Technology, \\ Huazhong University of Science and Technology, Wuhan 430074, P. R. China \\ ${ }^{2}$ State Key Laboratory of Multiphase Complex Systems, Institute of Process Engineering, \\ Chinese Academy of Science, Beijing 100190, P. R. China \\ ${ }^{3}$ State Key Laboratory of Advanced Technology for Materials Synthesis and Processing, \\ Wuhan University of Technology, Wuhan 430070, P. R. China
}

(Received July 26, 2013; accepted February 10, 2014)

Key words: flat-type coplanar gas sensor arrays, acetone, $\mathrm{SnO}_{2}$ films, in situ DRIFTS

$\mathrm{SnO}_{2}$ flat-type coplanar gas sensor arrays were fabricated by a screen-printing technique based on $\mathrm{SnO}_{2}$ nanopowders prepared by a sol-gel method. The $\mathrm{SnO}_{2}$ flat-type coplanar gas sensor arrays had good acetone gas-sensing characteristics such as a fast response, short recovery time, and an almost linear response to acetone concentration of 1-100 ppm. The response could reach 2.11 for acetone concentration as low as $1 \mathrm{ppm}$, and the response and recovery times for $1 \mathrm{ppm}$ acetone were 8.9 and $10 \mathrm{~s}$, respectively. The surface reactions were investigated by in situ diffuse reflectance infrared Fourier transform spectroscopy (DRIFTS) at different temperatures, and a possible sensing mechanism was proposed. Formate, acetate, carbonate ions, $\mathrm{CH}_{3} \mathrm{O}_{(\mathrm{ads})}, \mathrm{CO}_{2}, \mathrm{H}_{2} \mathrm{O}$, and adsorbed acetone were detected when the $\mathrm{SnO}_{2}$ flims were exposed to $100 \mathrm{ppm}$ acetone at different temperatures.

\section{Introduction}

Metal oxide semiconductor (MOS) nanomaterials, such as $\mathrm{ZnO}, \mathrm{In}_{2} \mathrm{O}_{3}, \mathrm{Ga}_{2} \mathrm{O}_{3}, \mathrm{WO}_{3}$, and $\mathrm{SnO}_{2}$, have attracted considerable attention because of their unique properties and potential applications in various nanodevices. Among them, $\mathrm{SnO}_{2}$, a stable and largebandgap (n-type) semiconductor, has been widely used owing to its low cost, long life, good reproducibility, ${ }^{(1-3)}$ and ability to detect low-level concentrations. ${ }^{(4)} \mathrm{SnO}_{2}$-based sensors are used for various purposes, including detecting flammable gases in the home

*Corresponding author: e-mail: huangkaijin@hust.edu.cn 
or office, detecting $\mathrm{H}_{2}{ }^{(5)}$ ethanol, ${ }^{(6)} \mathrm{H}_{2} \mathrm{~S}$, ${ }^{(7)}$ and $\mathrm{LPG}^{(8)}$ to prevent leakage, and detecting $\mathrm{CO}^{(9)}$ to prevent incomplete combustion. The gas sensitivity of oxides is often divided into bulk- and surface-sensitive materials, while $\mathrm{SnO}_{2}$ belongs to the category of surfacesensitive materials. ${ }^{(10)}$ The gas-sensing application of $\mathrm{SnO}_{2}$ is based on the change in the material resistance when exposed to different atmospheres, which is due to the charge carrier exchange between the adsorbed gas and the oxide surface. ${ }^{(11)}$

Acetone is commonly considered as a representative volatile organic compound, which can cause environmental hazards and is harmful to human health, ${ }^{(12)}$ and has been regarded as an important disease marker of diabetes and ketoacidosis. ${ }^{(13)}$ Therefore, it is very important to monitor and control its content in the human blood stream, human breath, and environments. Some studies have demonstrated the monitoring and detection of acetone. A trace amount of acetone $(<0.9 \mathrm{ppm})$ is found as a normal constituent in the expiration of a healthy person, whereas a higher value indicates a possible diabetic condition. ${ }^{(14)}$ Nasution et al. reported that the acetone concentration in the breath varies from 0.3 to $0.9 \mathrm{ppm}$ in healthy people to more than $1.8 \mathrm{ppm}$ for diabetics; ${ }^{(15)}$ this makes acetone a suitable chemical marker for diabetes diagnosis. Hence, the monitoring of low-level acetone concentration is of utmost importance for human health and for precisely diagnosing diabetes mellitus in patients. To date, gas chromatography (GC), gas chromatography-mass spectrometry (GC-MS), solid-phase microextraction (SPME), chemical sensors, SPME with GC-MS, GC-MS, and SPME with on-fiber derivatization, and membrane extraction with sorbent interface have been applied to acetone detection. ${ }^{(13)}$ These methods all have low concentration limits. For example, GC provided detection limits of $1-5 \mathrm{ppb}$ for several volatile compounds including acetone gas, ${ }^{(16)}$ and GCMS and SPME with on-fiber derivatization provided a low detection limit of $0.049 \mathrm{ppb}$ for acetone in breath. ${ }^{(13)}$ However, these methods are expensive and time-consuming, requiring considerable experimental setup. Moreover, owing to its volatility and activity, it is very difficult to accurately measure the concentration of acetone in human breath. ${ }^{(13)}$

Recently, several gas sensors have been developed for acetone detection. ${ }^{(17-20)}$ For example, the gas-sensing performance of the porous spherelike $\mathrm{ZnO}$-nanostructure-based sensor for acetone has been investigated, and the results revealed that the sensor had an optimum operating temperature of $310^{\circ} \mathrm{C}$, good stability for low-concentration acetone ( $2 \mathrm{ppm}$ acetone at $310^{\circ} \mathrm{C}$ ), and good selectivity at $310^{\circ} \mathrm{C} .{ }^{(17)}$ The response value of a hollow and mesoporous $\mathrm{ZnO}$-microsphere-based sensor was 2 in 5 ppm acetone, and the response and recovery times are 3 and $11 \mathrm{~s}$ when exposed to $5 \mathrm{ppm}$ acetone, respectively. ${ }^{(18)}$ The sensitivity of $1.5 \%$ Ag-modified $\mathrm{NiFe}_{2} \mathrm{O}_{4}$ gas sensor to acetone gas reaches 43 , which is 4 times higher than that of the pure $\mathrm{NiFe}_{2} \mathrm{O}_{4}$ sample, and the quick response time (1 s) and fast recovery time $(\sim 10 \mathrm{~s})$ are the main characteristics of this sensor. ${ }^{(19)}$ The $\mathrm{WO}_{3}$ $\mathrm{Cr}_{2} \mathrm{O}_{3}$ semiconducting thin films exhibit excellent acetone vapor sensing properties with the maximum sensitivity of $\sim 8.91$ at $320{ }^{\circ} \mathrm{C}$ in air atmosphere with fast response and recovery times. ${ }^{(20)}$

So far, the ranges of study of the acetone gas sensor were focused on the improvement of its gas-sensing properties including the synthesis of gas-sensing materials with special morphology, doping of gas-sensing materials, and fabrication of heterojunction gas-sensing materials. A few studies reported the reaction behaviours 
between the acetone gas and gas-sensing materials. The ultrahigh sensitivity of $\mathrm{Au} / 1 \mathrm{D}$ $\alpha-\mathrm{Fe}_{2} \mathrm{O}_{3}$ to acetone was tested and a possible sensing mechanism was investigated by in situ diffuse reflectance infrared Fourier transform spectroscopy (DRIFTS) technology. The results showed that $\mathrm{Au} / 1 \mathrm{D} \alpha-\mathrm{Fe}_{2} \mathrm{O}_{3}$ had a fast response, short recovery time, and an almost linear response to the acetone concentration. ${ }^{(14)}$ In this paper, we focused on the problem concerning acetone and $\mathrm{SnO}_{2}$ films by using in situ DRIFTS technology.

In fact, in situ DRIFTS has been used to investigate the gas-solid adsorption relationships between different gases and different gas-sensing materials. ${ }^{(14,21-25)}$ For example, Gunawan et al. ${ }^{(14)}$ reported the possible acetone-sensing mechanism on $\mathrm{Au} / 1 \mathrm{D}$ $\alpha-\mathrm{Fe}_{2} \mathrm{O}_{3}$ films based on DRIFTS. Tian et al. ${ }^{(21)}$ reported the possible formaldehydesensing mechanism on $\mathrm{SnO}_{2}$ films based on DRIFTS at $190{ }^{\circ} \mathrm{C}$. Huang et al. ${ }^{(22)}$ reported the formaldehyde gas adsorption and reactions on $\gamma-\mathrm{Fe}_{2} \mathrm{O}_{3}$ films by in situ DRIFTS. Chen et al. ${ }^{(23)}$ reported the $\mathrm{NO}_{2}$-sensing mechanism on $\mathrm{ZnO}$ films by in situ DRIFTS. Chiorino et al. ${ }^{(24)}$ reported the $\mathrm{NO}_{2}$ adsorption and oxidation on $\mathrm{MoO}_{x}-\mathrm{SnO}_{2}$ films by in situ DRIFTS. Besselmann et al.(25) reported the toluene adsorption and oxidation on $\mathrm{V}_{2} \mathrm{O}_{5} / \mathrm{TiO}_{2}$ catalysts by Raman spectroscopy and in situ DRIFTS.

In this paper, $\mathrm{SnO}_{2}$ flat-type coplanar acetone gas sensor arrays were fabricated by a screen-printing technique based on nano- $\mathrm{SnO}_{2}$ powders prepared by a sol-gel method. The temperature- and concentration-dependent behaviors of the $\mathrm{SnO}_{2}$ gas sensor arrays to acetone are investigated. Tracing the surface reaction by in situ DRIFTS sheds valuable light on the oxidation pathway and how this relates to the sensing mechanism.

\section{Materials and Methods}

\subsection{Materials, synthesis of $\mathrm{SnO}_{2}$ nanopowders, characterization of $\mathrm{SnO}_{2}$ nanopowders, and measurements of gas-sensing properties}

The $\mathrm{SnO}_{2}$ nanopowders were prepared by a sol-gel method, (26) the $\mathrm{SnO}_{2}$ flat-type coplanar gas sensor arrays were fabricated by a screen-printing technique, and the $\mathrm{SnO}_{2}$ nanopowders were examined by XRD and FESEM techniques.

In addition, the gas sensitivity was measured in the static state. The measuring electric circuit for gas sensors was the same as in ref. 1. The test equipment was assembled in our laboratory. The working temperature of sensors was adjusted by varying the heating voltage. The correlation between heating voltage and working temperature is shown in Table 1. First, the gas sensor arrays were fixed in a 30-liter test chamber, then the test system was started and the voltage to meet the working temperature was adjusted according to Table 1 . When the baseline was stable, a certain amount of acetone liquid was injected into the heating plate of the sealing device with a microliter syringe. The gas sensitivity in this paper was defined as $S=R_{\mathrm{a}} / R_{\mathrm{g}}$, where $R_{\mathrm{a}}$ and $R_{\mathrm{g}}$ were the resistances of a sensor in air and in a test gas, respectively. The response time was defined as the time required for the variation in conductance to reach $90 \%$ of the equilibrium value after a test gas was injected, and the recovery time as the time necessary for the sensor to return to $10 \%$ above the original conductance in air after releasing the test gas. 
Table 1

Correlation between heating voltage and working temperature.

\begin{tabular}{lccccc}
\hline Temperature $\left({ }^{\circ} \mathrm{C}\right)$ & 200 & 250 & 300 & 320 & 350 \\
\hline Voltage $(\mathrm{V})$ & 4.8 & 5.4 & 6.2 & 6.5 & 7.0 \\
\hline
\end{tabular}

\subsection{Fabrication of flat-type coplanar gas sensor arrays}

Gas sensors were made from pre-prepared pure $\mathrm{SnO}_{2}$ powders. The final powders were mixed and ground with an organic solution in an agate mortar to form a gassensing paste. Then, the paste was printed onto an alumina substrate with pre-printed $\mathrm{Au}$ interdigital electrodes (with a gap of about $0.2 \mathrm{~mm}$ ) and a $\mathrm{RuO}_{2}$ heater by the screenprinting technique, then sintered at $550{ }^{\circ} \mathrm{C}$ for $2 \mathrm{~h}$. Lastly, gold wires and a welding machine were used to weld the gas sensor arrays onto TO-8-003 supports to form gas-sensing devices, and then aged at $250{ }^{\circ} \mathrm{C}$ for $3 \mathrm{~d}$ in air to enhance their stability. Following the above procedures, the $\mathrm{SnO}_{2}$ flat-type coplanar gas sensor arrays were obtained as shown in Fig. 1.

\subsection{In situ DRIFTS measurement}

The adsorption and reactions of acetone on $\mathrm{SnO}_{2}$ films were studied by in situ DIRFTS. All spectra were recorded at $200-300{ }^{\circ} \mathrm{C}$ on a VERTEX 70 FT-IR spectrometer (Bruker) equipped with a liquid-nitrogen-cooled mercury cadmium telluride detector with a range of 4000-600 $\mathrm{cm}^{-1}$ and a diffuse reflection accessory with a controlled environment and temperature reflectance cell, equipped with $\mathrm{KBr}$ windows, averaging 128 scans with a $4 \mathrm{~cm}^{-1}$ resolution and analysed using OPUS software. In each DRIFTS experiment, a certain amount of $\mathrm{KBr}$ powders was located in the reactive cell with the $\mathrm{SnO}_{2}$ films $\left(2.8 \times 2.8 \mathrm{~mm}^{2}\right)$ on top of the powders, which was connected with a vacuum chamber for materials treatment to obtain reproducible reflecting planes. In addition, the temperature of the reactive cell was controlled using a thermostat ranging from room temperature to $600{ }^{\circ} \mathrm{C}$. A pretreatment process at $200{ }^{\circ} \mathrm{C}$ and $5.0 \times 10^{-3} \mathrm{~Pa}$ was performed for $15 \mathrm{~min}$ to make the sample reproducible, and the spectra of $\mathrm{KBr}$ powders were recorded for use as the background. A gas stream $(30 \mathrm{ml} / \mathrm{min})$ of 100 ppm acetone was introduced into the cell at different temperatures, and the spectra were recorded after the sample was pretreated and heated to the predetermined temperature under flowing acetone gas. A background spectrum was collected before each test. Spectra were measured in Kubelka-Munk (K-M) units: $F\left(R_{\infty}\right)=K / S=\left(1-R_{\infty}\right)^{2} / 2 R_{\infty}$, where $K, S$, and $R_{\infty}$ are the absorption coefficient, scattering coefficient, and reflectance of an infinite thick layer, respectively. When the scattering coefficient $S$ is a constant, the Kubelka-Munk function $F\left(R_{\infty}\right)$ is proportional to the absorption coefficient $K$ at a given wavelength. Since the scattering coefficient $S$ varies only slightly with the wave number of the IR radiation, the shape of the K-M spectrum mirrors the wave number dependence of the absorption coefficient $K$. Therefore, the K-M function is usually used as the IR absorption spectrum..$^{(27)}$ 


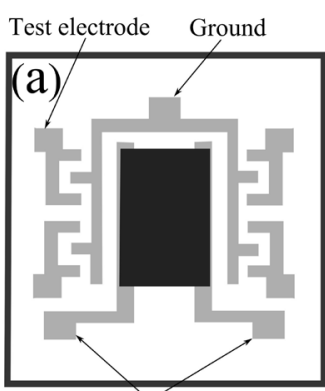

Heater electrode

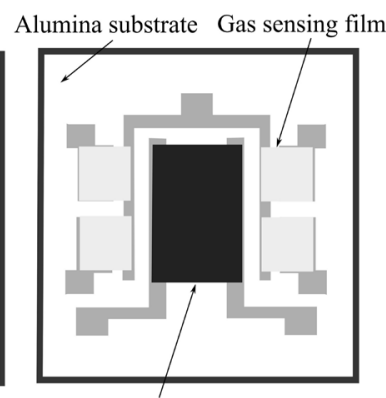

$\mathrm{RuO}_{2}$ heater

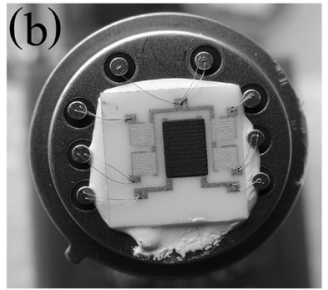

Fig. 1. (a) Schematic diagram of the flat-type coplanar gas sensor arrays and (b) actual picture of the $\mathrm{SnO}_{2}$ flat-type coplanar gas sensor arrays.

\section{Results and Discussion}

\subsection{Characterization of $\mathrm{SnO}_{2}$ nanopowders}

Figure 2 shows the XRD patterns of the $\mathrm{SnO}_{2}$ nanopowders. The diffraction peaks are in good agreement with JCPDS no. 77-0452 and can therefore be indexed as the crystalline rutile structure of $\mathrm{SnO}_{2}$ with lattice constants of $a=4.7552 \mathrm{~nm}$ and $c=3.1992$ $\mathrm{nm}$. The diffraction peaks are relatively broadened, indicating the small crystallite size. The crystallite sizes of the nanopowders were calculated using the Scherrer formula: ${ }^{(28)}$ $D=0.89\{\lambda / \beta \cos \theta\}$, where $D$ is the mean grain size, $\lambda$ is the wavelength of the X-rays ( $\lambda=0.15406 \mathrm{~nm}$ for $\mathrm{Cu} \mathrm{K \alpha}$ radiation), and $\beta$ is the full width at half maximum of the diffraction peak at $2 \theta$. The calculated average grain size is about $12 \mathrm{~nm}$.

Figure 3 shows the FESEM images of $\mathrm{SnO}_{2}$ nanopowders. The $\mathrm{SnO}_{2}$ nanopowders are spherical and uniformly dispersed with diameters of approximately 10-20 nm. This value is of coincidence with the calculated result according to the XRD pattern of the $\mathrm{SnO}_{2}$ nanopowders.

\subsection{Gas-sensing properties of $\mathrm{SnO}_{2}$ flat-type coplanar gas sensor arrays}

To optimize the operating temperature to achieve the best gas response, $100 \mathrm{ppm}$ acetone was used as the standard, and the sample gas response was evaluated from 200 to $350{ }^{\circ} \mathrm{C}$, as shown in Fig. 4. The gas responses increase with operating temperature, become maximum at $320^{\circ} \mathrm{C}$, and begin to decrease above this temperature. Operating at $320^{\circ} \mathrm{C}$, the gas sensor can obtain a maximum gas response. The changes in gas response with operating temperature can be attributed to the fact that the adsorption types of oxygen molecules are chemisorption at higher temperature and physisorption at lower temperature. The reaction rates of acetone and adsorbed oxygen ion increase when the working temperature becomes high, which determine the existence of an equilibrium density of oxygen ions and cause a larger change in the resistance. Hence, the gas 

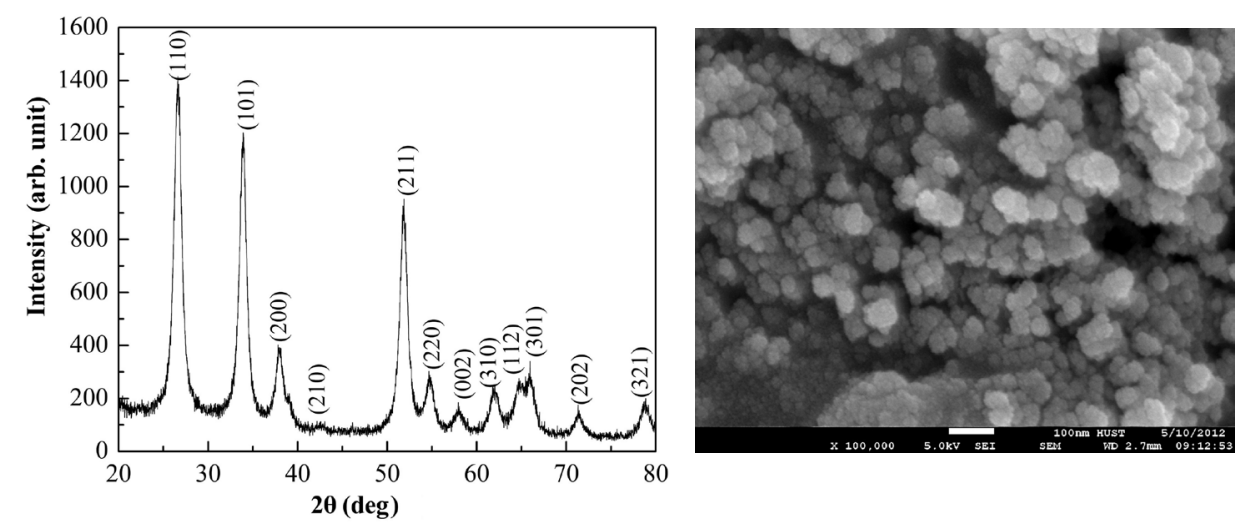

Fig. 2 (left). XRD patterns of $\mathrm{SnO}_{2}$ nanopowders.

Fig. 3 (right). FESEM images of $\mathrm{SnO}_{2}$ nanopowders.

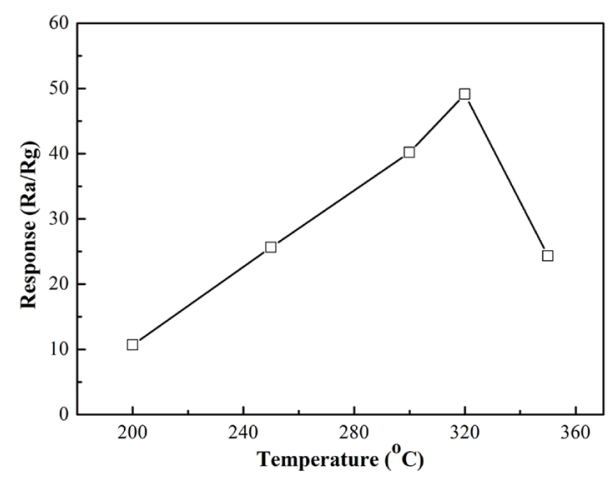

Fig. 4. Gas responses of $\mathrm{SnO}_{2}$ flat-type coplanar gas sensor arrays to $100 \mathrm{ppm}$ acetone at different operating temperatures.

responses are enhanced with increasing temperature. The adsorption attains a dynamic equilibrium of absorption-desorption at a proper temperature because the chemisorption is an exothermic reaction. If the working temperature keeps increasing, the reactants begin to combust, resulting in the dynamic equilibrium bias to desorption. Given its volatile nature, the steady-state level of absorbed acetone molecules will decrease progressively, and the balance will move to desorption, resulting in a decreased gas response above $320^{\circ} \mathrm{C} .(29,30)$

The concentration of the adsorbates may be approximated from simple adsorption models. In the Lennard-Jones model, the rate of chemisorption is determined by an activation barrier between a physisorbed state and the chemisorbed state and an activation barrier of desorption as illustrated in the literature. ${ }^{(10)}$ Using this model, the 
rate of chemisorption $\mathrm{d} \Theta / \mathrm{d} t$ is expressed as the difference in adsorption and desorption rates:

$$
\mathrm{d} \Theta / \mathrm{d} t=k_{\mathrm{ads}} \exp \left\{-\Delta E_{\mathrm{A}} / k T\right\}-k_{\mathrm{des}} \Theta \exp \left\{-\left(\Delta E_{\mathrm{A}}+\Delta H_{\text {chem }}\right) / k T\right\},
$$

where $\Delta E_{\mathrm{A}}$ is the activation barrier for chemisorption and $\Delta H_{\text {chem }}$ is the heat of chemisorption. Under steady-state conditions, $\mathrm{d} \Theta / \mathrm{d} t=0$, i.e, the rate of adsorption is equal to the rate of desorption; the coverage $\Theta$ is dependent on the heat of chemisorption $\Delta H_{\text {chem }}$ and is given by

$$
\Theta=k_{\text {ads }} / k_{\text {des }} \exp \left\{\Delta H_{\text {chem }} / k T\right\} .
$$

Thus, generally, the coverage will decrease with temperature. At low temperatures, the molecules are, however, trapped in a physisorbed state and cannot overcome the activation barrier $\Delta E_{\mathrm{A}}$. This results in a maximum coverage at a temperature $T_{\max }$ as illustrated in the literature. ${ }^{(10)}$ Hence, this theory further illustrates that the gas responses increase with operating temperature, become maximum at a certain temperature, and begin to decrease above this temperature.

As a typical n-type semiconductor, $\mathrm{SnO}_{2}$ belongs to the category of surface-sensitive materials. The change in resistance is dependent on the species and chemisorbed oxygen on the surface. The adsorbed oxygen changes to various oxygen anion species transferring an electron from $\mathrm{SnO}_{2}$ to the chemisorbed oxygen; negatively charged chemisorbed oxygen species cause an upward band bending and consequently a depletion layer in the near-surface region. This causes a Schottky-like barrier across grain boundaries, leading to the increase in the resistance of the sensor. The process can be expressed in the following equations:

$$
\begin{aligned}
& \mathrm{O}_{2(\mathrm{~g})} \leftrightarrow \mathrm{O}_{2(\mathrm{ads})} \\
& \mathrm{O}_{2(\text { ads })}+\mathrm{e}^{-} \leftrightarrow \mathrm{O}_{2}{ }^{-} \text {(ads) } \\
& \mathrm{O}_{2}^{-}{ }_{(\mathrm{ads})}+\mathrm{e}^{-} \leftrightarrow 2 \mathrm{O}^{-}{ }_{\text {(ads) }} \\
& \mathrm{O}^{-}{ }_{(\text {ads })}+\mathrm{e}^{-} \leftrightarrow \mathrm{O}^{2-}{ }_{(\text {ads })}
\end{aligned}
$$

wherein "g" and "ads" refer to gas and adsorbate, respectively. A transition temperature of $150^{\circ} \mathrm{C}$ was found among the chemisorbed oxygen species. Below this temperature, oxygen adsorption on the surface was mainly in the form of $\mathrm{O}_{2}^{-}$, while above 150 ${ }^{\circ} \mathrm{C}$, chemisorbed oxygen in the form of $\mathrm{O}^{-}$or $\mathrm{O}^{2-}$ was found. ${ }^{(10)}$ After acetone was introduced, it would be oxidized by these chemisorbed oxygen species $\left(\mathrm{O}_{2}^{-}, \mathrm{O}^{-}, \mathrm{O}^{2-}\right)$ on the surface of the test sensor. During the reaction, the electrons went back into the semiconductor, resulting in a decrease in resistance of the sensor. When the sensor was exposed to air again, the gases are desorbed as $\mathrm{H}_{2} \mathrm{O}$ and $\mathrm{CO}_{2}$. This reaction process may be expressed in the following equation. 


$$
\mathrm{CH}_{3} \mathrm{COCH}_{3(\mathrm{ads})}+8 \mathrm{O}^{-}{ }_{\text {(ads) }} \rightarrow 3 \mathrm{CO}_{2}+3 \mathrm{H}_{2} \mathrm{O}+8 \mathrm{e}^{-}
$$

Figure 5 shows the corresponding sensitivities of the $\mathrm{SnO}_{2}$ gas sensor arrays versus acetone concentration in the range of $1-100 \mathrm{ppm}$. These measurements were performed by injecting various amounts of testing vapors into a sealed chamber at the operating temperature of $320^{\circ} \mathrm{C}$. From the figure, it is observed that the gas response increases more or less linearly as a function of acetone concentration in the measured range. Such a linear dependence of the sensitivity further shows that the sensors can be used as promising sensors for trace acetone detection, which is consistent with other gases. ${ }^{(31)}$

The fit curve, namely, the logarithm of the sensitivity $(\lg S)$ as a function of the $\operatorname{logarithm}$ of the acetone gas concentration $(\lg C)$, is shown in Fig. 6. The relationship between sensitivity $S$ and concentration $C$ can be depicted as $\lg S=\lg A+N \lg C$, where $A$ is a constant, modified with the microstructure and surface reaction of materials, and $N$ is an exponent between 0.5 and 1.0, relating to the morphology of the material and the stoichiometry of the elements on the surface. ${ }^{(32)}$ In this curve, the correlation coefficient $R$ of the sensor fit curve is 0.97383 , and the curve fitting shows the linear relationship as follows.

$$
\lg S=1.78+0.67492 \lg C
$$

As shown here, when the acetone concentration was in the range of 1-100 ppm, the logarithm of sensitivity showed good linearity with the logarithm of acetone concentration. The result shows that the sensors match with dilogarithm amplifying circuits for practical application in the detection range of 1-100 ppm acetone vapor.

Figure 7 shows the typical isothermal response curves obtained at various acetone concentrations from 1 to $100 \mathrm{ppm}$. Short response and recovery times can be observed. The gas response of the sensors can reach 2.11 for acetone concentration as low

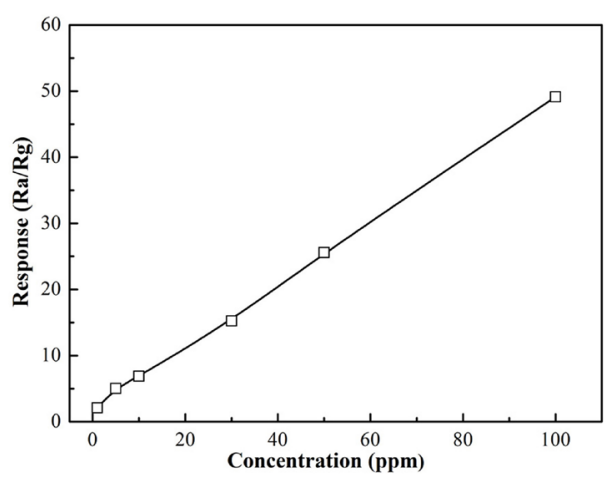

Fig. 5. Gas responses of $\mathrm{SnO}_{2}$ flat-type coplanar gas sensor arrays to different concentrations of acetone at $320^{\circ} \mathrm{C}$ as the operating temperature. 

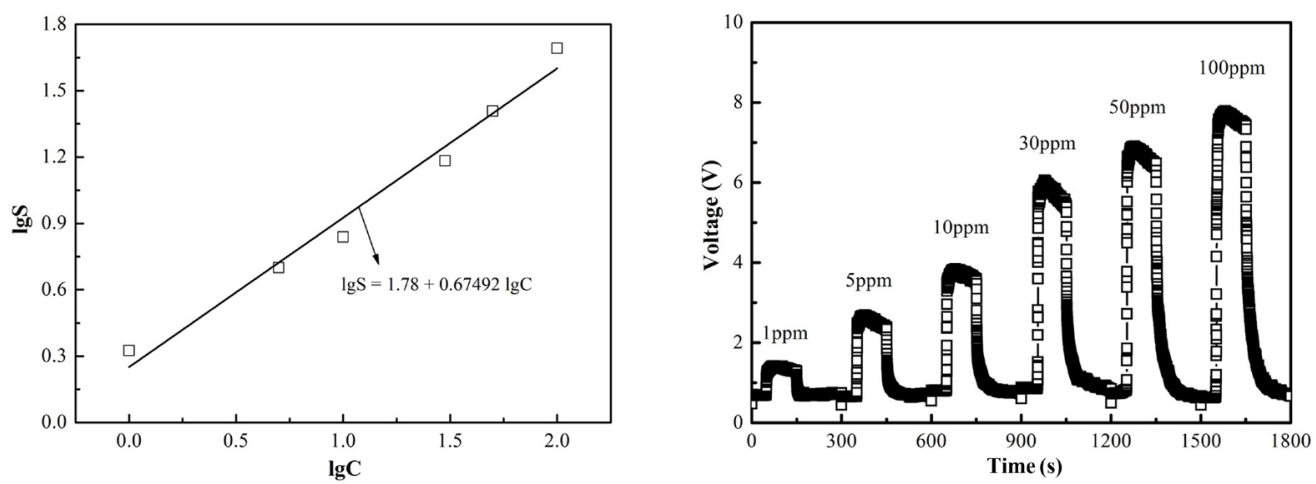

Fig. 6 (left). Dilogarithm fit curve of the gas responses versus the concentration of acetone at 320 ${ }^{\circ} \mathrm{C}$.

Fig. 7 (right). Typical response-recovery curves of the $\mathrm{SnO}_{2}$ flat-type coplanar gas sensor arrays to different acetone concentrations at $320^{\circ} \mathrm{C}$.

as $1 \mathrm{ppm}$, and the response and recovery times for $1 \mathrm{ppm}$ acetone are 8.9 and $10 \mathrm{~s}$, respectively. It is close to the concentration of $0.9 \mathrm{ppm}$ found as a normal constituent in the expiration of a healthy person ${ }^{(13)}$ and lower than the concentration of $1.8 \mathrm{ppm}$ for diabetics. ${ }^{(15)}$ These concentrations are much lower than the threshold limit value (TLV) of acetone vapor in our living environment (750 ppm) according to the American Conference of Governmental Industrial Hygienists. ${ }^{(33)}$

\subsection{In situ DRIFTS study}

To investigate the acetone-sensing mechanism on $\mathrm{SnO}_{2}$ films, the in situ DRIFTS technique was used to study the reaction process of acetone and $\mathrm{SnO}_{2}$ films. The information on the reaction process was noted by the appearance of adsorbed species in the initial stages of adsorption. Figures 8-11 show the representative time-resolved DRIFTS spectra of the $\mathrm{SnO}_{2}$ films in a flow of $100 \mathrm{ppm}$ acetone at 200, 250, 320, and $350{ }^{\circ} \mathrm{C}$, respectively. The IR assignments of acetone adsorption on $\mathrm{SnO}_{2}$ films at different temperatures are shown in Table 2.(12,14,34-41)

Figure 8 shows the representative time-resolved DRIFTS spectra of acetone adsorption on the $\mathrm{SnO}_{2}$ films at $200{ }^{\circ} \mathrm{C}$. After 5 min when the $\mathrm{SnO}_{2}$ films are exposed to actone , the strong bands are at 3786, 3698, 3582, 2968, 2929, 2873, 2382, and $2307 \mathrm{~cm}^{-1}$, and the weak bands are at 1731, 1591, 1555, 1411, 1234, 1163, and $1113 \mathrm{~cm}^{-1}$. The first three sharp bands $\left(3786,3698\right.$, and $3582 \mathrm{~cm}^{-1}$ ) associated with isolated hydroxyl groups $[v(\mathrm{OH})]$ tended to increase in intensity with time. ${ }^{(34)}$ This was likely due to the formation of water as a product of the oxidation of acetone. The bands at $2968,{ }^{(12,14,35,36)} 1731^{(12,14,37)}$ $2929,{ }^{(14,34,36,38)}$ and $1234 \mathrm{~cm}^{-1(12,14,35,36)}$ could be assigned to molecularly adsorbed acetone $[v(\mathrm{C}-\mathrm{H}), v(\mathrm{C}=\mathrm{O})$, and $v(\mathrm{C}-\mathrm{C})$, respectively], and the intensity of the bands became weaker with time, indicating the decrease in the amount of adsorbed acetone 
Table 2

IR assignments of acetone adsorption on $\mathrm{SnO}_{2}$ films at different temperatures.

\begin{tabular}{|c|c|c|c|c|c|}
\hline Surface species & $\begin{array}{l}\text { Wave number } \\
\left(\mathrm{cm}^{-1}\right)\left(200^{\circ} \mathrm{C}\right)\end{array}$ & $\begin{array}{l}\text { Wave number } \\
\left(\mathrm{cm}^{-1}\right)\left(250^{\circ} \mathrm{C}\right)\end{array}$ & $\begin{array}{l}\text { Wave number } \\
\left(\mathrm{cm}^{-1}\right)\left(320^{\circ} \mathrm{C}\right)\end{array}$ & $\begin{array}{l}\text { Wave number } \\
\left(\mathrm{cm}^{-1}\right)\left(350^{\circ} \mathrm{C}\right)\end{array}$ & Reference \\
\hline$v(\mathrm{OH})$ & $3786 / 3698$ & $3732 / 3387 / 3241$ & $3793 / 3705 / 3668$ & $3790 / 3738 / 3644$ & (44) \\
\hline$v(\mathrm{C}-\mathrm{H})$ & $2968 / 2929$ & 2961 & $3019 / 2928$ & & $(12,14,35-38)$ \\
\hline $\begin{array}{l}v_{\mathrm{a}}(\mathrm{COO})+ \\
\delta(\mathrm{CH})\end{array}$ & & & & 2951 & $(35,36,38)$ \\
\hline$v_{\mathrm{S}}(\mathrm{CH})$ & 2873 & 2890 & & & $(35,36)$ \\
\hline $\mathrm{CO}_{2}$ & $2382 / 2307$ & $2378 / 2327$ & $2389 / 2356 / 2318$ & $2381 / 2355 / 2306$ & $(39,40)$ \\
\hline$v(\mathrm{C}=\mathrm{O})$ & 1731 & 1685 & 1737 & $1753 / 1722$ & $(12,14,35-38)$ \\
\hline$\delta(\mathrm{OH})$ & & 1647 & & & (35) \\
\hline$v_{\mathrm{a}}(\mathrm{COO})$ & $1591 / 1555$ & & $1581 / 15187$ & 1517 & $(14,36,41)$ \\
\hline$v\left(\mathrm{CO}_{3}^{-}\right)$ & & 1440 & 1440 & 1441 & $(12,35,36)$ \\
\hline$\delta(\mathrm{CH})$ & 1411 & 1380 & 1320 & 1395 & $(36,38)$ \\
\hline$v(\mathrm{C}-\mathrm{C})$ & 1234 & & 1255 & 1255 & $(12,14,35,36)$ \\
\hline$v(\mathrm{C}-\mathrm{O})$ & $1163 / 1113$ & 1110 & 1110 & & (41) \\
\hline$\delta(\mathrm{CCH})$ & & & & 1092 & (36) \\
\hline
\end{tabular}
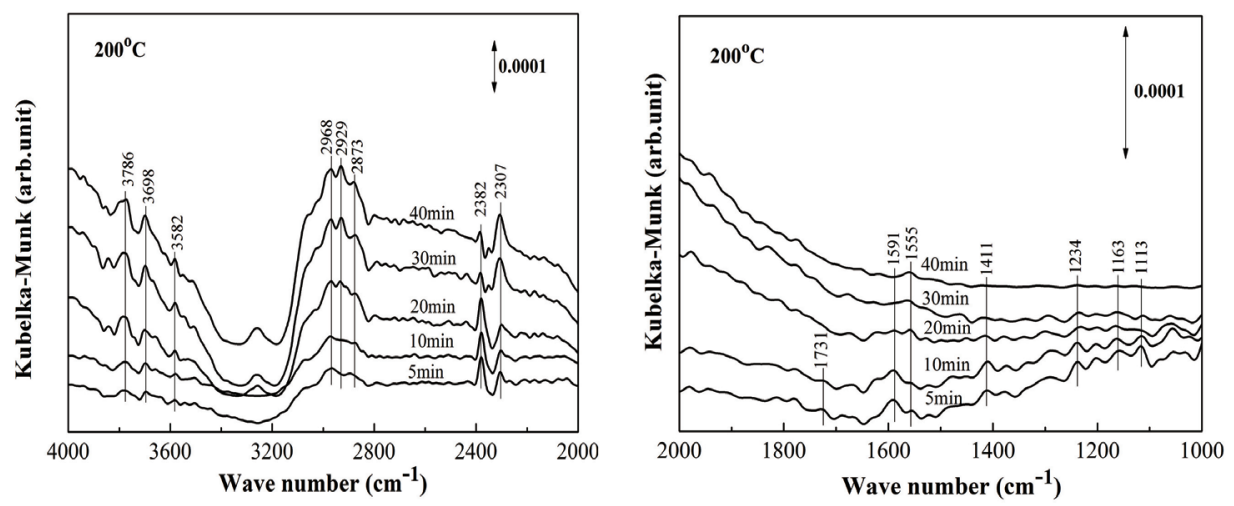

Fig. 8. In situ DRIFTS spectra of $100 \mathrm{ppm}$ acetone adsorption on $\mathrm{SnO}_{2}$ films at $200{ }^{\circ} \mathrm{C}$.

molecules because the intensity of 1234 and $1731 \mathrm{~cm}^{-1}$ became weaker with time. The bands at $2873,{ }^{(35,36)} 1591,{ }^{(36)} 1411,{ }^{(36)}$ and $1555 \mathrm{~cm}^{-1(14)}$ were due to the surface formate $\left[v_{\mathrm{s}}(\mathrm{CH}), v_{\mathrm{as}}(\mathrm{COO})\right.$, and $\delta_{\mathrm{s}}(\mathrm{CH})$, respectively] and acetate $\left[v_{\mathrm{as}}(\mathrm{COO})\right]$. This implied the dissociative chemisorption of acetone with $\mathrm{C}-\mathrm{C}$ bond cleavage. Moreover, two adsorption bands of $\mathrm{CO}_{2}$ were shown at 2382 and $2307 \mathrm{~cm}^{-1}$ in the carbon dioxide region. ${ }^{(39,40)}$ The absorption bands due to $\mathrm{C}-\mathrm{O}$ stretching of monodentate $\mathrm{CH}_{3} \mathrm{O}_{\text {(ads) }}$ peaked at 1163 and $1113 \mathrm{~cm}^{-1} \cdot{ }^{(41)}$

Figure 9 shows the DRIFTS spectra of acetone adsorption on the $\mathrm{SnO}_{2}$ films at $250{ }^{\circ} \mathrm{C}$. It could be seen from the figure that the adsorption reached a steady level in 

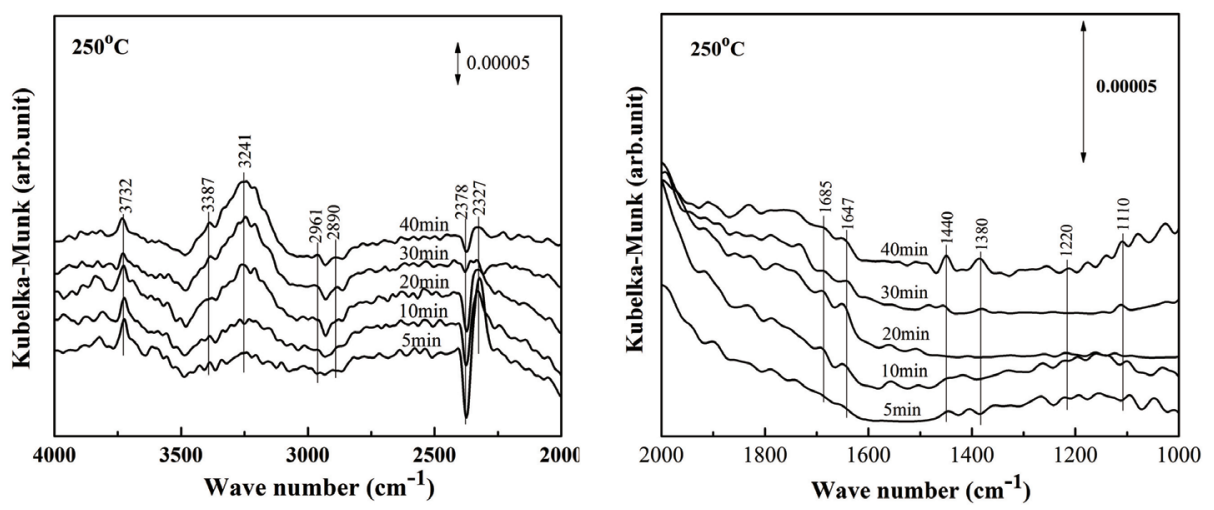

Fig. 9. In situ DRIFTS spectra of $100 \mathrm{ppm}$ acetone adsorption on $\mathrm{SnO}_{2}$ films at $250{ }^{\circ} \mathrm{C}$.

5 min and some bands were measured. The bands at 3732 and $3241 \mathrm{~cm}^{-1}$, which were accompanied by a weak band at $3387^{(34)}$ and $1647 \mathrm{~cm}^{-1},{ }^{(35)}$ were related to the $v(\mathrm{OH})$ and $\delta(\mathrm{OH})$ modes of different types of isolated hydroxyl group, respectively. No peaks assigned to acetate species were observed in the spectrum shown in this figure, while the new band at $1685 \mathrm{~cm}^{-1(35,38)}$ was assigned to the characteristic peak of molecularly adsorbed acetone. The bands at $2890^{(35,36)}$ and $1380 \mathrm{~cm}^{-1(38)}$ were related to $v_{\mathrm{s}}(\mathrm{CH})$ and $\delta(\mathrm{CH})$ of formate species, respectively. The intensity of the bands at 2400-2300 $\mathrm{cm}^{-1}$ assigned to $\mathrm{CO}_{2}$ was greater than that at $200{ }^{\circ} \mathrm{C}$, indicating that the reaction was increasingly rapid with increasing temperature. ${ }^{(39,40)}$ The gradual evolution of the IR bands at $1220 \mathrm{~cm}^{-1(14)}$ corresponded to the symmetric bends of $\mathrm{CO}_{2}$ adsorbed in the bent configuration, a quite labile species. The band at $1110 \mathrm{~cm}^{-1}$ was assigned to the $\mathrm{C}-\mathrm{O}$ stretching of $\mathrm{CH}_{3} \mathrm{O}_{(\mathrm{ads})}{ }^{(41)}$ Finally, Coronado et al. ascribed the peak at $1440 \mathrm{~cm}^{-1}$ to the $v_{\mathrm{s}}(\mathrm{COO})$ mode of surface acetate, ${ }^{(38)}$ but the current results suggest that the rather intense band at $1440 \mathrm{~cm}^{-1}$ was observable, showing that the $\mathrm{COO}$ symmetric stretching $v_{\mathrm{s}}\left(\mathrm{CO}_{3}^{-}\right)$ of surface monodentate carbonates, ${ }^{(12,35,36)}$ a likely partial oxidation product, tended to increase owing to their more stable properties. The possible mechanism for acetone decomposition may be shown as the following eqs. (9)-(15).

$$
\begin{aligned}
& \mathrm{CH}_{3} \mathrm{COCH}_{3(\mathrm{~g})} \rightarrow \mathrm{CH}_{3} \mathrm{COCH}_{3(\mathrm{ads})} \\
& \mathrm{CH}_{3} \mathrm{COH}_{3(\mathrm{ads})}+2 \mathrm{O}^{-}{ }_{(\mathrm{ads})} \rightarrow \mathrm{CH}_{3} \mathrm{COO}^{-}{ }_{(\mathrm{ads})}+\mathrm{CH}_{3} \mathrm{O}^{-}{ }_{(\mathrm{ads})} \\
& \mathrm{CH}_{3} \mathrm{O}^{-}{ }_{\text {(ads) }}+2 \mathrm{O}^{-}{ }_{\text {(ads) }} \rightarrow \mathrm{HCOO}^{-}{ }_{\text {(ads) }}+\mathrm{H}_{2} \mathrm{O}+2 \mathrm{e}^{-} \\
& 2 \mathrm{CH}_{3} \mathrm{COO}^{-}{ }_{\text {(ads) }}+5 \mathrm{O}^{-}{ }_{\text {(ads) }} \rightarrow 4 \mathrm{HCOO}^{-}{ }_{\text {(ads) }}+\mathrm{H}_{2} \mathrm{O}_{(\mathrm{ads})}+3 \mathrm{e} \\
& 2 \mathrm{CH}_{3} \mathrm{COO}^{-}{ }_{\text {(ads) }}+11 \mathrm{O}^{-}{ }_{\text {(ads) }} \rightarrow 4 \mathrm{CO}_{3}{ }^{2-}{ }_{\text {(ads) }}+3 \mathrm{H}_{2} \mathrm{O}_{\text {(ads) }}+5 \mathrm{e}^{-} \\
& 2 \mathrm{HCOO}^{-}{ }_{\text {(ads) }}+3 \mathrm{O}^{-}{ }_{\text {(ads) }} \rightarrow 2 \mathrm{CO}_{3}{ }^{2-}{ }_{(\mathrm{ads})}+\mathrm{H}_{2} \mathrm{O}+\mathrm{e}^{-}
\end{aligned}
$$




$$
\mathrm{CO}_{3}{ }^{2-}{ }_{\text {(ads) }} \rightarrow \mathrm{CO}_{2}
$$

The DRIFTS spectra of acetone adsorption on the $\mathrm{SnO}_{2}$ films at $320{ }^{\circ} \mathrm{C}$ are shown in Fig. 10. All the peaks were quite intense at this temperature, which was in accord with the gas-sensing properties (Fig. 4). In addition, the band intensities increased with the progression of the reaction, indicating an active reaction on the surface. The bands at 3793,3705 , and $3668 \mathrm{~cm}^{-1}$ were due to the isolated surface $\mathrm{OH}$ groups, and tended to increase in intensity with time. ${ }^{(34)}$ The new bands at $3019^{(36)}$ and $1255^{(12,14,35,36)}$ $\mathrm{cm}^{-1}$ were due to $\mathrm{C}-\mathrm{H}$ symmetric stretching $\mathrm{v}(\mathrm{C}-\mathrm{H})$ and $\mathrm{C}-\mathrm{C}$ symmetric stretching $v(\mathrm{C}-\mathrm{C})$, respectively, of molecularly adsorbed acetone, and the band at $1737^{(12,14,37)}$ $\mathrm{cm}^{-1}$ corresponded to the characteristic peak of acetone. Three rather intense bands at $2400-2300^{(39,40)} \mathrm{cm}^{-1}$ were observable in the carbon dioxide region, which were greater than those at 200 and $250{ }^{\circ} \mathrm{C}$, owing to the reaction running actively at this temperature according to the results shown in Fig. 4. In addition, the new bands at $1581^{(36)}$ and $1320^{(35)} \mathrm{cm}^{-1}$ observed could be associated with the asymmetric $\mathrm{COO}^{-}$ stretching vibration $v_{\text {as }}(\mathrm{COO})$ and the deformation vibration $\delta(\mathrm{CH})$ of the formate species, respectively, while the $1517^{(41)} \mathrm{cm}^{-1}$ band could be associated with the $v_{\text {as }}(\mathrm{COO})$ of surface acetate species. Meanwhile, the bands at $1440^{(12,35,36)}$ and $1404^{(12,35)} \mathrm{cm}^{-1}$ were typical peaks of surface carbonate species. The deconvoluted band of $\mathrm{CH}_{3} \mathrm{O}_{\text {(ads) }}$ was located at $1110 \mathrm{~cm}^{-1}$ at this temperature. ${ }^{(41)}$ Molecular acetone, formate, acetate, $\mathrm{CH}_{3} \mathrm{O}_{\text {(ads) }}$, carbonate, $\mathrm{H}_{2} \mathrm{O}$, and $\mathrm{CO}_{2}$ spectral features appeared in the infrared spectrum. We can infer that when the sensor was exposed to acetone gas, the gas was initially adsorbed on the surface. Then, the adsorbed acetone gas was oxidized to form $\mathrm{CH}_{3} \mathrm{O}_{\text {(ads) }}$ and acetate by chemisorbed oxygen species. The formate, a one-carbon-containing species, may originate from the photoreaction of the $\mathrm{CH}_{3} \mathrm{O}_{(\mathrm{ads})}$ or the two-carboncontaining species of acetate. Formate and acetate species, as reaction intermediates, were further converted to carbonate species. Finally, $\mathrm{CO}_{2}$ was formed after the oxidation of carbonate ions.
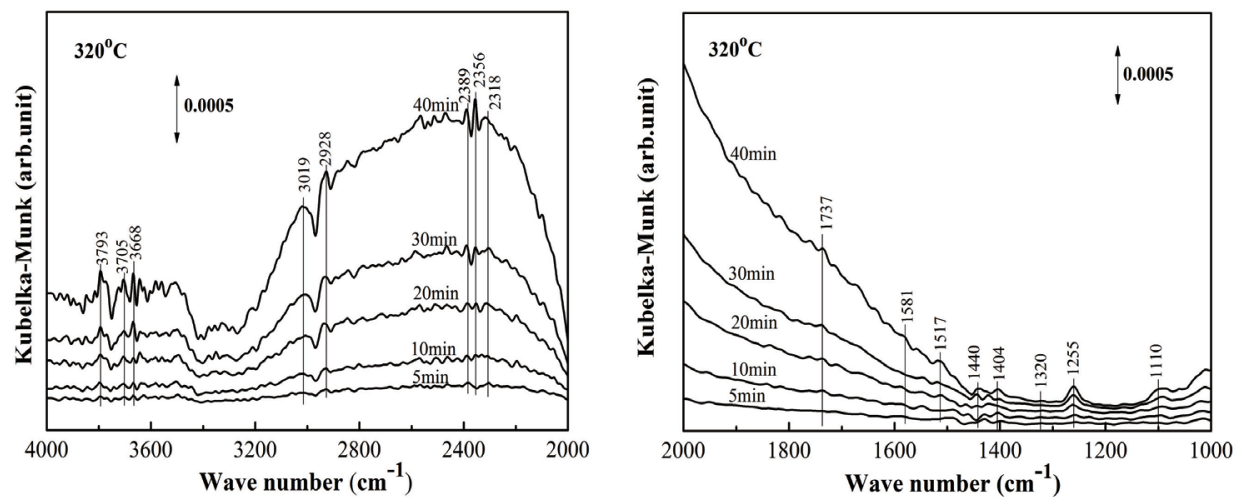

Fig. 10. In situ DRIFTS spectra of $100 \mathrm{ppm}$ acetone adsorption on $\mathrm{SnO}_{2}$ films at $320^{\circ} \mathrm{C}$. 
Figure 11 shows the representative time-resolved DRIFTS spectra corresponding to the adsorption of acetone on the $\mathrm{SnO}_{2}$ films at $350{ }^{\circ} \mathrm{C}$. Compared with Fig. 10, the bands were relatively weak, possibly because of the rapid desorption at higher temperature. A certain amount of surface-isolated hydroxyl groups at 3790, 3738, and $3644 \mathrm{~cm}^{-1}$ observed at sharp bands of high frequencies could be due to the formation of water. ${ }^{(34)}$ The new bands at $2951^{(35,36,38)}$ and $1395^{(38)} \mathrm{cm}^{-1}$ were assigned to the $\left[v_{\text {as }}(\mathrm{COO})\right.$ $+\delta(\mathrm{CH})]$ and $\delta(\mathrm{CH})$, respectively, of formate species. On the other hand, the bands at $1753^{(36)}$ and $1722^{(14,36)} \mathrm{cm}^{-1}$ could correspond to the characteristic peak of formate. The weak band at $1517^{(41)} \mathrm{cm}^{-1}$ was due to the $\mathrm{COO}$ antisymmetric stretching $v_{\mathrm{as}}(\mathrm{COO})$ of acetate. Meanwhile, the peak at $1441 \mathrm{~cm}^{-1}$ was assigned to the $v_{\mathrm{s}}\left(\mathrm{CO}_{3}^{-}\right)$mode of free carbonates. ${ }^{(12,35,36)}$ Moreover, the spectrum showed three quite intense bands at 2381, 2355, and $2306^{(39,40)} \mathrm{cm}^{-1}$ in the carbon dioxide region, and the absorption band at 1092 $\mathrm{cm}^{-1}$, assigned to the deformation vibration $\delta(\mathrm{CCH})$, confirms the presence of molecular acetone.(36) The oxidation of acetone on $\mathrm{SnO}_{2}$ films at this temperature was shown according to eqs. (9)-(15).

On the basis of the results, we find that the intensities of the bands of all the adsorbed species on the $\mathrm{SnO}_{2}$ films showed obvious changes with temperature. When the temperature was increased from 200 to $320^{\circ} \mathrm{C}$, the intensity of spectra strengthened with time. However, when the temperature was increased to $350{ }^{\circ} \mathrm{C}$, very weak adsorptions on the surface could still be observed. This was consistent with the variation tendency of the gas response and the operating temperature of the sensor. The formate, acetate, $\mathrm{CH}_{3} \mathrm{O}_{\text {(ads) }}$, and carbonate were the important reaction intermediates for acetone adsorption on the surface of $\mathrm{SnO}_{2}$ films, while $\mathrm{CO}_{2}$ and $\mathrm{H}_{2} \mathrm{O}$ were the final products. These observations suggest that the acetone molecules break after the attack of the chemisorbed oxygen species $\left(\mathrm{O}_{2}^{-}, \mathrm{O}^{-}, \mathrm{O}^{2-}\right)$ to yield a two-carbon molecule and a single carbon one. Thus, a simplified reaction scheme for the mechanism study of acetone on the $\mathrm{SnO}_{2}$ films was proposed and shown in Fig. 12.
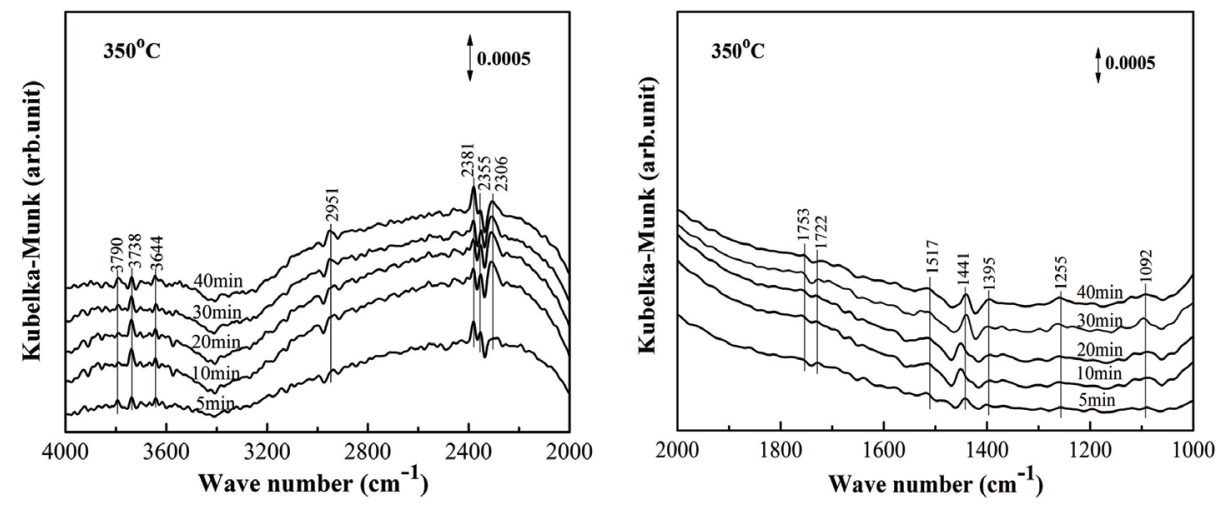

Fig. 11. In situ DRIFTS spectra of $100 \mathrm{ppm}$ acetone adsorption on $\mathrm{SnO}_{2}$ films at $350{ }^{\circ} \mathrm{C}$. 


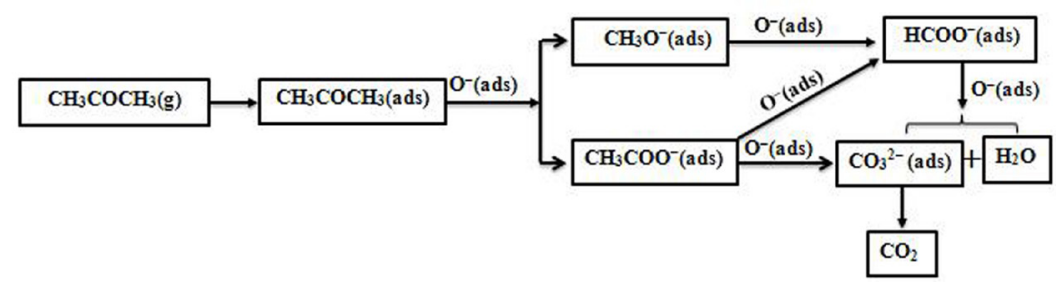

Fig. 12. Possible mechanism of acetone adsorption and reactions on $\mathrm{SnO}_{2}$ films.

\section{Conclusions}

$\mathrm{SnO}_{2}$ flat-type coplanar acetone gas sensor arrays were successfully fabricated by a screen-printing technique based on $\mathrm{SnO}_{2}$ nanopowders prepared by a sol-gel method. The gas-sensing properties in relation to $1-100 \mathrm{ppm}$ acetone were tested. The gas response increased more or less linearly as a function of acetone concentration in 1-100 ppm, which further showed that the sensors could be used as promising sensors for acetone detection in this concentration range. The gas response could reach 2.11 for acetone concentration as low as $1 \mathrm{ppm}$, and the response and recovery times for $1 \mathrm{ppm}$ acetone were 8.9 and $10 \mathrm{~s}$, respectively. Thus, the $\mathrm{SnO}_{2}$ sensors could realize the realtime detection of acetone. The sensing mechanism was elucidated by the in situ DRIFTS technique based on the main adsorbed species during the adsorption. The in situ DRIFTS experimental results revealed that formate, acetate, $\mathrm{CH}_{3} \mathrm{O}_{\text {(ads) }}$, carbonate ions, $\mathrm{H}_{2} \mathrm{O}, \mathrm{CO}_{2}$, and molecularly adsorbed acetone surface species were formed during the interaction of acetone with $\mathrm{SnO}_{2}$ films at $200-350{ }^{\circ} \mathrm{C}$.

\section{Acknowledgements}

This work was supported by the Opening Project (MPCS-2011-D-13) of the State Key Laboratory of Multiphase Complex Systems, Institute of Process Engineering, Chinese Academy of Science, and the Opening Project (2012-KF-4) of the State Key Laboratory of Advanced Technology for Materials Synthesis and Processing (Wuhan University of Technology). The authors are also grateful to the Analytical and Testing Center of Huazhong University of Science and Technology.

\section{References}

1 X. H. Ding, D. W. Zeng and C. S. Xie: Sens. Actuators, B 149 (2010) 336.

2 T. Maekawa, K. Suzuki, T. Takada, T. Kobayashi and M. Egashira: Sens. Actuators, B 80 (2001) 51.

3 S. C. Ray, M. K. Karanjai and D. DasGupta: Surf. Coat. Technol. 102 (1998) 73.

4 F. L. Meng, H. H. Li, L. T. Kong, J. Y. Liu, Z. Jin, W. Li, Y. Jia, J. H. Liu and X. J. Huang: Anal. Chim. Acta. 736 (2012) 100.

5 T. Ohgali, R. Matsuota, K. Watanabe, K. Matsumoto, Y. Adachi, I. Sakaguchi, S. Hishita, N. Ohashi and H. Haneda: Sens. Actuators, B 150 (2010) 99. 
6 S. Q. Liu, M. J. Xie, Y. X. Li, X. F. Guo, W. J. Ji, W. P. Ding and A. Chaktong: Sens. Actuators, B 151 (2010) 229.

7 W. A. Mir, K. Usmah and Q. Ahsanulhaq: Curr. Nanosci. 8 (2012) 919.

8 J. K. Srivastava, P. Pandey, V. N. Mishra and R. Dwivedi: Solid State Sci. 11 (2009) 1602.

9 W. Thorsten, C. D. Kohl, F. Michael and T. Michael: Sensors 6 (2006) 318.

10 M. Batzill and U. Diebold: Prog. Surf. Sci. 79 (2005) 47.

11 U. Hoefer, J. Frank and M. Fleischer: Sens. Actuators, B 78 (2001) 6.

12 L. Y. Wan, X. Y. Li, Z. P. Qu, Y. Shi, H. Li, Q. D. Zhao and G. H. Chen: J. Hazard. Mater. 184 (2010) 864.

13 C. H. Deng, J. Zhang, X. F. Yu, W. Zhang and X. M Zhang: J. Chromatogr. B 810 (2004) 269.

14 P. Gunawan, L. Mei. J. Teo, J. M. Ma, J. Highfield, Q. H. Li and Z. Y. Zhong: Langmuir. 28 (2012) 14090.

15 T. I. Nasution, I. Nainggolan, S. D. Hutagalung, K. R. Ahmad and Z. A. Ahmad: Sens. Actuators, B 177 (2013) 522.

16 J. M. Sanchez and R. D. Sacks: Anal. Chem. 75 (2003) 2231.

17 X. B. Li, S. Y. Ma, F. M. Li, Y. Chen, Q. Q. Zhang, X. H. Yang, C. Y. Wang and J. Zhu: Mater. Lett. 100 (2013) 119.

18 J. Rao, A. Yu, C. L. Shao and X. F. Zhou: ACS Appl. Mater. Interfaces. 4 (2012) 5346.

19 W. J. Jiao and L. Zhang: Trans. Nonferrous Met. Soc. China. 22 (2012) 1127.

20 P. Gao, H. M. Ji, Y. G. Zhou and X. L. Li: Thin Solid Films 520 (2012) 3100.

21 S. Q. Tian, X. H. Ding, D.W. Zeng, J. J. Wu, S. P. Zhang and C. S. Xie: R. Soc. Chem. 3 (2013) 11823.

22 K. J. Huang, L. C. Kong, F. L. Yuan and C. S. Xie: Appl. Surf. Sci. 38 (2013) 405.

23 M. Chen, Z. H. Wang, D. M. Han, F. B. Gu and G. S. Guo: Sens. Actuators, B 157 (2011) 565.

24 A. Chiorino, G. Ghiotti, F. Prinetto, M. C. Carotta, D. Gnani and G. Martinelli: Sens. Actuators, B 58 (1999) 338.

25 S. Besselmann, E. LÖffler and M. Muhler. J. Mol. Catal. A: Chem. 162 (2000) 401.

26 K. J. Huang, Z. X. Zhang, F. L. Yuan and C. S. Xie: Curr. Nanosci. 9 (2013) 357.

27 L. Tolvaj, K. Mitsui and D. Varga: Wood. Sci. Technol. 45 (2011) 135.

28 S. W. Choi, J. Zhang, K. Akash and S. S. Kim: Sens. Actuators, B 169 (2012) 54.

29 C. S Xie, L. Q. Xiao, M. L. Hu, Z. K. Bai, X. P. Xiao and D. W. Zeng: Sens. Actuators, B 145 (2010) 457.

30 X. W. Dong, L. P. Qin, J. Q. Xu, Q. Y. Pan, Z. X. Cheng and Q. Xiang: Curr. Nanosci. 4 (2008) 236.

31 L. V. Thong, N. D. Hoa, D. T. T. Le, D. T. Viet, P. D. Tam, A. T. Le and N. V. Hieu: Sens. Actuators, B 146 (2010) 361.

32 L. Yu, M. Zhang, Y. J. Chen, H. M. Zhang, Q. H. Li, E. D. Zhang and Z. Xu: Solid State Sci. 14 (2012) 522.

33 L. P. Qin, J. Q. Xu, X. W. Dong, Q. Y. Pan, Z. X. Cheng, Q. Xiang and F. Li: Nanotechnology. 19 (2008) 185705.

34 K. Grossmann, G. R. Pavelko, N. Barsan and U. Weimar: Sens. Actuators, B 166-167 (2012) 787.

35 M. El-Maazawi, A. N. Finken, A. B. Nair and V. H. Grassian: J. Catal. 191 (2000) 138.

36 H. Song and X. P. Zhou: J. Mol. Catal. 22 (2008) 454 (in Chinese).

37 A. C. Ferraz and R. Miotto: Appl. Surf. Sci. 234 (2004) 185.

38 J. M. Coronado, S. Kataoka, I. Tejedor-Tejedor and M. A. Anderson: J. Catal. 219 (2003) 219.

39 W. Z. Xu, D. Raftery and J. S. Francisco: J. Phys. Chem. B 107 (2003) 4537.

40 X. Du, Y. Du and S. M. George: J. Phys. Chem. A 112 (2008) 9211.

41 W. C. Wu, C. C. Chuang and J. L. Lin: J. Phys. Chem. B 104 (2000) 8719. 